\title{
Spatial and statistical analysis of leptospirosis in Thailand from 2013 to 2015
}

\author{
Amornrat Luenam, ${ }^{1}$ Nattapong Puttanapong ${ }^{2}$ \\ ${ }^{1}$ Faculty of Public and Environmental Health, Huachiew Chalermprakiet University, Samut Prakan; \\ ${ }^{2}$ Faculty of Economics, Thammasat University, Khlong Luang, Thailand
}

\begin{abstract}
This study analyzes the temporal pattern and spatial clustering of leptospirosis, a disease recognized as an emerging public health problem in Thailand. The majority of those infected are farmers and fishermen. Severe epidemics of leptospirosis in association with the rainy reason have occurred since 1996. Still, an understanding of the annual variation and spatial clustering of the disease is lacking. Data were collected from the Center of Epidemiological Information, Bureau of Epidemiology, Ministry of Public Health, covering the nationwide incidence of leptospirosis during the period 2013-2015. Clustering techniques, including local indicators of spatial association and local Getis-Ord Gi* statistic, were used for the analysis and evaluation of the annual spatial distribution of the disease. Both these
\end{abstract}

Correspondence: Amornrat Luenam, Faculty of Public and Environmental Health, Huachiew Chalermprakiet University, Samut Prakan, 10540, Thailand.

Tel.: +66.089.112.2289.

E-mail: luenam.hcu@gmail.com

Key words: Leptospirosis; Local indicators of spatial association; Local Getis-Ord Gi* statistic; Thailand.

Acknowledgments: the authors are grateful to the Center of Epidemiological Information, Bureau of Epidemiology, Ministry of Public Health, Thailand, for sharing data used in the research.

Contributions: $\mathrm{AL}$, data collection, spatial analysis, and writing manuscript ; NP, study conception, verification of analysis and review of the manuscript.

Conflict of interest: the authors declare no potential conflict of interest.

Funding: none.

Ethical statement: the Ethical Committee of Huachiew Chalermprakiet University, Thailand, deemed this study to be exempt from requiring ethical approval (reference no A.693/2561).

Received for publication: 17 September 2018.

Revision received: 21 January 2019.

Accepted for publication: 22 January 2019.

(C) Copyright A. Luenam and N. Puttanapong, 2019

Licensee PAGEPress, Italy

Geospatial Health 2019; 14:739

doi:10.4081/gh.2019.739

This article is distributed under the terms of the Creative Commons Attribution Noncommercial License (CC BY-NC 4.0) which permits any noncommercial use, distribution, and reproduction in any medium, provided the original author(s) and source are credited. statistics revealed similar results for the areas with the highest clustering patterns of leptospirosis. Specifically, there were persisting hotspots in north-eastern and southern parts of Thailand over the three years covered by the study. This outcome suggests that healthcare resources should be allocated to the areas characterized by leptospirosis clustering.

\section{Introduction}

Leptospirosis is caused by a spirochete of the genus Leptospira that can be transmitted by both wild and domestic animals with rodents, livestock and dogs as common animal reservoirs (WHO, 2003). The symptoms of leptospirosis in humans vary from fever to serious complications that can include kidney damage, liver failure, respiratory distress and meningitis (Tangkanakul et al., 2005; WHO, 2015). Treatment consists of antibiotics, which should be given early in the course of infection. Late diagnosis can lead to death.

According to World Health Organization (WHO), the estimated global leptospirosis incidence is 0.1 to 1 per 100,000 people in temperate climates, while it can be 10 to 100 times more common in tropical climates, particularly if there is an epidemic (WHO, 2003; 2015). The disease is underreported for many reasons, including the difficulty in distinguishing clinical signs from those of other endemic diseases and lack of appropriate diagnostic laboratory services.

Transmission of the bacteria occurs via water when contaminated with urine from infected animals, which is the main cause of spread of the infection to soil, food and water bodies (Faine, 1994). Moreover, leptospirosis can survive for a long period of time in aqueous environments such as water and moist soil, from where it rapidly propagates during warm temperatures (Ridzlan et al., 2010; Honarmand and Eshraghi, 2011). It can thus be an occupational hazard for people, such as veterinarians, cattlemen, farmers, fishermen, miners, sewage workers and garbage collector who work outdoors and have physical contact with contaminated water and soil (Tangkanakul et al., 2005; WHO, 2015). Farmers are mostly infected during cultivation activities, e.g., ploughing and fertilizing. Catching fish in environments associated with contaminated water is also a hazard (Victoriano et al., 2009). Thus, there are many risks due to interactions between humans, animal reservoirs and the environment that can lead to infection. According to conventional leptospirosis epidemiology, rural areas report more cases of infection than urban ones because of the environmental factors mentioned (Wiwanitkit, 2006). Outbreaks typically occur during the rainy season, which means that the weather is one of the major factors influencing the spread of the bacteria (Lau et al., 2012). Leptospirosis has been recognized as an emerging public health problem in Thailand with severe epidemics occurring since 
1996 (Tangkanakul et al., 2005). The annual numbers of leptospirosis cases reported to the Ministry of Public Health (MoPH) were 3,093, 2,251 and 2,151 in year the years 2013, 2014 and 2015 , respectively (MoPH, 2006). Although the number of reported cases have decreased lately, epidemics are still a serious concern. Various tools to assess the disease have been used, but an analysis of spatial distribution and possible clusters, especially at the national level, have rarely been investigated. Although the spatial component has been investigated, efforts to study the distribution of leptospirosis in Thailand have mostly been concentrated on individual patients and characterisation of the spread of the disease by infected animals (Myint et al., 2007; Chadsuthi et al., 2017). For these reasons, this study aimed to also analyze the spatio-temporal distribution and the possibility of clustering at the provincial level. The findings should facilitate prevention of leptospirosis and would also serve as a supporting evidence for researchers, academics and public health officials not only with regard to epidemics of this infection alone but also concerning other diseases.

\section{Materials and Methods}

\section{Study area and seasons}

The study concerned Thailand as a whole, which occupies an area of $514,000 \mathrm{~km}^{2}: 511,770 \mathrm{~km}^{2}$ of land and 2,230 $\mathrm{km}^{2}$ of water. There are 77 provinces, 878 districts (Amphoe), 7,225 sub-districts (Tambon) and 74,965 villages (Mooban). There are three seasons: cold from November to February, hot from March to May and a rainy season from June to October.

\section{Data sources}

This longitudinal study used the incidence of leptospirosis per 100,000 people, reported by the Center of Epidemiological Information, Bureau of Epidemiology, MoFP, covering the period 2013-2015. The data included numbers of cases for all 77 provinces in the country, i.e. a total of 7,495 cases distributed over the study period. The data are publicly available at the National Disease Surveillance website (National Disease Surveillance, 2019). Officially, the criterion of being infected by these bacteria is defined as having leptospirosis diagnosed previously by a physician based on clinical diagnosis. The diagnostic codes used for the infection are A27.0-A27.9 according to the International Statistical Classification of Diseases and Related Health Problems, $10^{\text {th }}$ Revision (ICD-10).

\section{Data analysis}

The Quantum GIS (QGIS), version 2.18.20 (Steiniger and Hunter, 2013) and GeoDa were used for analyzing the data. First, QGIS was applied to geographically allocate the number of reported cases for each province during 2013-2015. Then, local clustering techniques were utilized for analyzing and evaluating the spatial distribution. Two spatial statistical methods, Moran's $I$, local Getis-Ord's $\mathrm{G}_{\mathrm{i}}{ }^{*}$ and local indicators of spatial association (LISA), were used. Since Thailand comprises one island province together with 23 coastal provinces and 32 border ones, the spatial weight matrix of $3 \mathrm{k}$-nearest neighbour was used in order to optimize the sufficient number of neighbouring provinces as well as to maintain the localized characteristics. The outcome of Moran's I identifies the intensity of spatial autocorrelation at various level of statistical significance, i.e. the P-value (Mitchell, 1999). The following mathematical representation exhibits the computation of Moran's $I$ :

$$
\begin{array}{r}
I=\frac{N}{S_{0}} \frac{\sum_{i=1}^{N} \sum_{j=1}^{N} W i j(x i-\bar{x})(x j-\bar{x})}{\sum_{i=1}^{N}(x i-\bar{x})(x i-\bar{x})^{2}} \\
S_{0}=\sum_{i=1}^{N} \sum_{j=1}^{N} W_{i j}
\end{array}
$$

where $W_{i j}$ is the spatial weight between the incidence of leptospirosis in provinces $i$ and $j ; N$ the total number of cases of infection recorded; $S_{0}$ the aggregate of all spatial weights; and $x_{i}, x_{j}$ the number of cases in provinces $i$ and $j$.

The obtained local indices denote the locations of leptospirosis cases and their spatial concentration. The observed spatial pattern of leptospirosis was unexpected or irrelative to the null hypothesis. The cluster detection was then extended to the local indicators of spatial association as proposed by Getis and Ord (1992) and Anselin (1995). In this paper, the analysis of the local indices included LISA and Getis-Ord $\mathrm{G}_{\mathrm{i}}{ }^{*}$ statistic, which are complementary. The LISA is the statistical significance test of positive or negative spatial correlation, while the local Getis-Ord $\mathrm{G}_{\mathrm{i}}$ * identifies whether the localized concentration is the zone of low or high attribute. The equation representing the computation of LISA is:

$$
\begin{gathered}
I_{i}=Z_{i} \sum_{i=1}^{N} W_{i j} Z_{j} \\
Z_{i}=\frac{\left(y_{i}-\bar{y}\right)}{S}
\end{gathered}
$$

where $W_{i j}$ is the spatial weight between $\mathrm{i}^{\text {th }}$ and $\mathrm{j}^{\text {th }}$ provinces; $Z_{i}, Z_{j}$ the value of $\mathrm{z}$-score in the $\mathrm{i}^{\text {th }}$ and $\mathrm{j}^{\text {th }}$ provinces; $Y_{i}$ the number of cases for the $\mathrm{i}^{\text {th }}$ province; and $S$ the aggregate of all spatial weights.

The Getis-Ord $\mathrm{G}_{\mathrm{i}}{ }^{*}$ statistic identifies those clusters of points with high magnitude (Mitchell, 1999). Particularly, this statistic was used for detecting clusters of similar values found in specific sub-regions of the study area (Anselin, 1995). The calculation was based on the following formula.

$$
G_{i}=\frac{\sum_{i \neq j} W_{i j} y_{j}}{\sum_{i=1}^{N} y_{i}}
$$

where $W_{i j}$ is the spatial weight between $\mathrm{i}^{\text {th }}$ and $\mathrm{j}^{\text {th }}$ provinces; and $y_{i}$, $y_{j}$ the number of cases for $\mathrm{i}^{\text {th }}$ and $\mathrm{j}^{\text {th }}$ provinces.

Moran $I$ results are expressed as high-high (HH), low-low (LL), low-high (LH) and high-low (HL) where HH represents provinces with high rates surrounded by areas with equally high rates, LL provinces with low rates surrounded by areas with equally low rates, LH provinces with few cases surrounded by areas with high numbers of cases, and HL provinces with high numbers surrounded by areas with low numbers. 


\section{Results}

During the three years 2013-2015, a total of 7,495 leptospirosis cases were reported. The annualized average number of infections was 4.83, 3.47, and 3.30 for year 2013, 2014 and 2015, respectively. A total number of deaths reported for this time span was 29, 24 and 51, respectively (Figure 1).

The provinces with many cases were found to be located in the eastern part of the Northeast, near the border to Cambodia and the Lao People's Democratic Republic. Provinces with many cases were also found in the upper part of the North near the Myanmar border. Moreover, there were high rates in some provinces in the South each year (Figure 2).

More than $50 \%$ of the patients affected by leptospirosis in the time period studied were farmers and fishermen underlining that workers in the agricultural and fishery sectors are at increased risk (Figure 3).

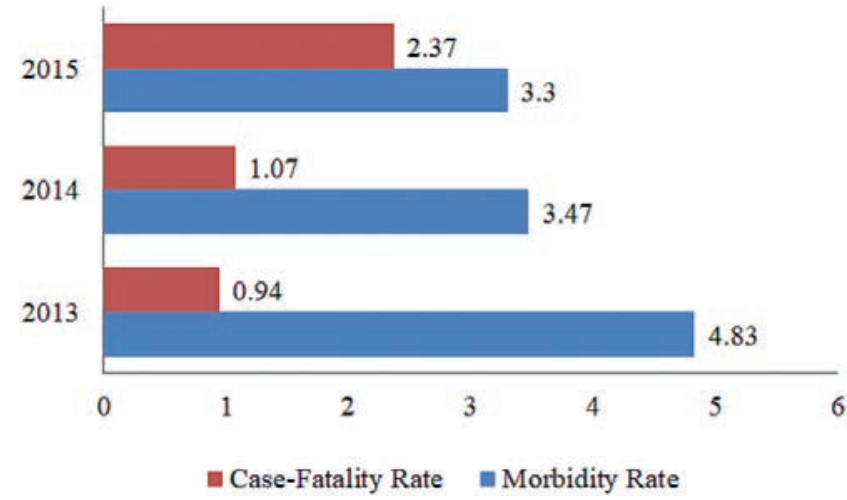

Figure 1. Annual leptospirosis incidence and case-fatality rate in Thailand from 2013 to 2015.
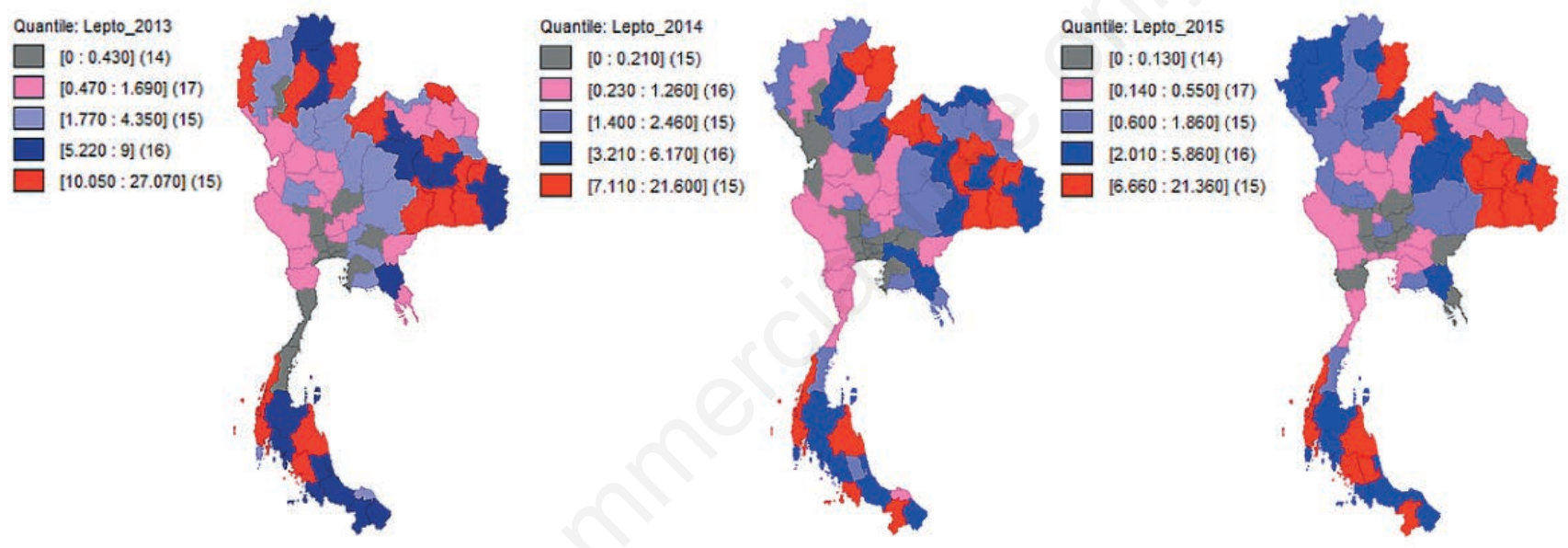

Figure 2. The annual average incidence of leptospirosis for each Thai province from 2013 to 2015.

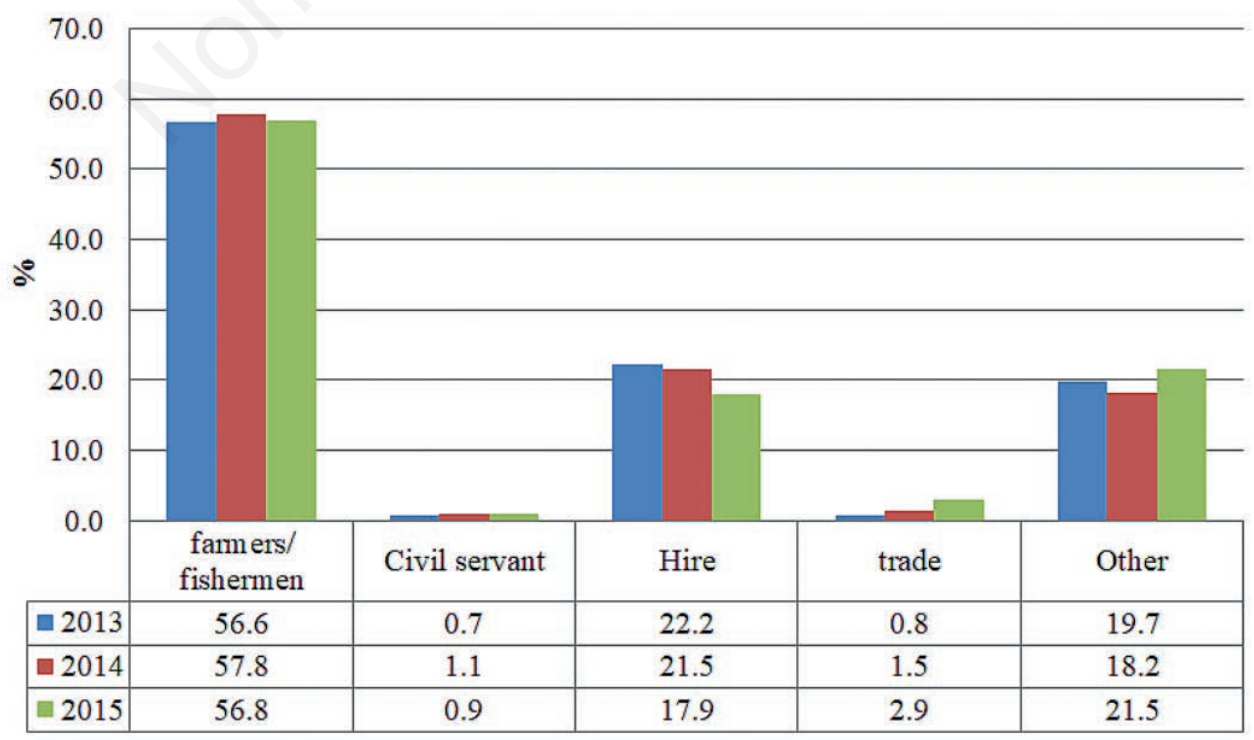

Figure 3. Percent of occupational leptospirosis from 2013 to 2015. 
The leptospirosis epidemics had a seasonal fluctuation with a high rate of detected cases occurring during the period JuneDecember, which is associated with the rainy reason. The highest number of cases was found in October of each year (Figure 4).

The univariate Moran's $I$ scatter of annual incidence of leptospirosis in 2013, 2014 and 2015 among Thailand's provinces showed a positive spatial autocorrelation. The Moran's I values for these years were $0.393,0.361$, and 0.453 , respectively, with a statistical level of significance ( $\mathrm{P}=0.05)$. The local Moran's $I$ method repeatedly showed $\mathrm{HH}$ and $\mathrm{LL}$ areas, in particular, two consistent patterns of $\mathrm{HH}$, indicating spatial autocorrelation of areas with high incidence of leptospirosis. The first was located in the northeastern region comprising Ubon Ratchathani, Si Sa Ket, Surin, Roi Et, Maha Sarakham and Yasothon provinces, while the second was located in the southern region including Ranong, Chumphon, Surat Thani, Krabi, Trang, and Phuket provinces (Figure 5). With respect to LL, spatial autocorrelation of low infection rates was consistently detected in the highly urbanized areas of Bangkok and surrounding provinces in the central region.

The local Getis-Ord Gi* statistic showed clusters located in the north-eastern and the southern regions consisting of Ubon Ratchathani, Si Sa Ket, Surin, Roi Et, Maha Sarakham, Yasothon, Ranong, Chumphon, Surat Thani, Krabi, Trang, and Phuket provinces, during all three years (Figure 6).

In summary, as seen in Figures 5 and 6, LISA, and the local Getis-Ord $\mathrm{G}_{i}{ }^{*}$ statistic revealed similar results for areas with the highest level of clustering of leptospirosis.

\section{Discussion}

This study shows the incidence of leptospirosis and the annual case-fatality rate in Thailand from 2013 to 2015 . The most likely reasons for some regions having higher incidence of leptospirosis than others are: i) climatological and ecological condition favouring the transmission of the disease during the rainy season (Levett, 2001; Panaphut et al., 2002; Tangkanakul et al., 2005; Parker and Walker, 2011; Suwanpakdee et al., 2015); ii) changing ecology and epidemiology of domestic animals and changes in agricultural practices (Heisey et al., 1988; Tangkanakul et al., 2005); iii) an increase of the density of rodents that increases the increased risk of infection (Tangkanakul, 2017).

As found here, these conditions put the north-eastern and the southern regions of Thailand at the highest risk with respect to leptospirosis as previously pointed out by Suwanpakdee et al. (2015). The main activities of these regions are rice farming and fishery (Panaphut et al., 2002; Watt et al., 2003; Suwanpakdee et al., 2015). The farmers are constantly in contact with soil and mud, while the sources of irrigation of the rice paddies are rivers and ponds, a preferable place for rodents (Victoriano et al., 2009; Suwanpakdee et al., 2015). Not surprisingly, there are more pronounced outbreaks in the rural areas than in the urbanized vicinities (Wiwanitkit, 2006). For example, Bangkok and its perimeter provinces, consisting of Samut Prakan, Nonthaburi, Pathum Thani and Nakhon Pathom, are urban environments with lower incidence of leptospirosis. With farmlands the most common leptospirosis

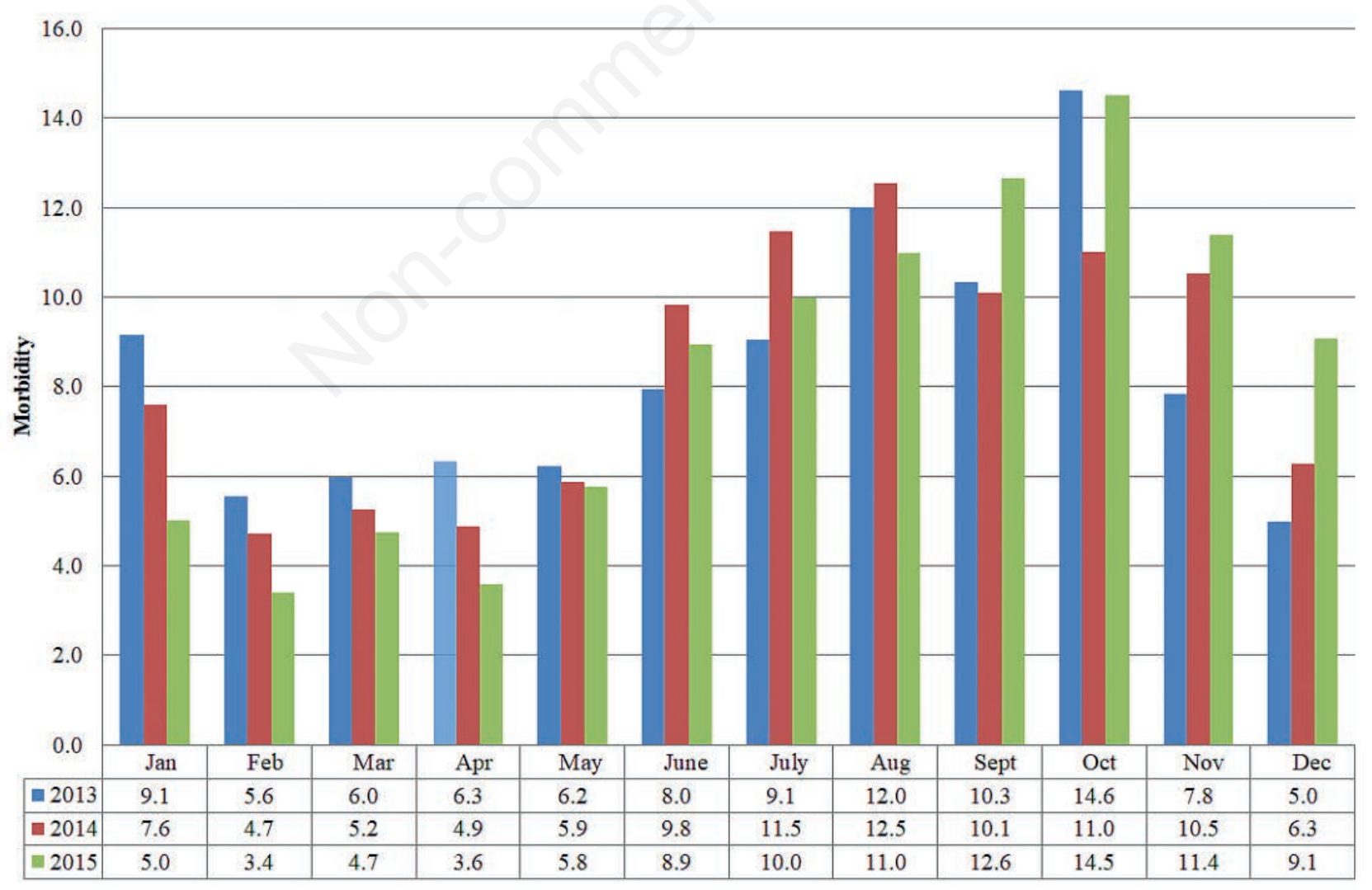

Figure 4. The monthly number of leptospirosis cases in all provinces in Thailand (2013-2015). 


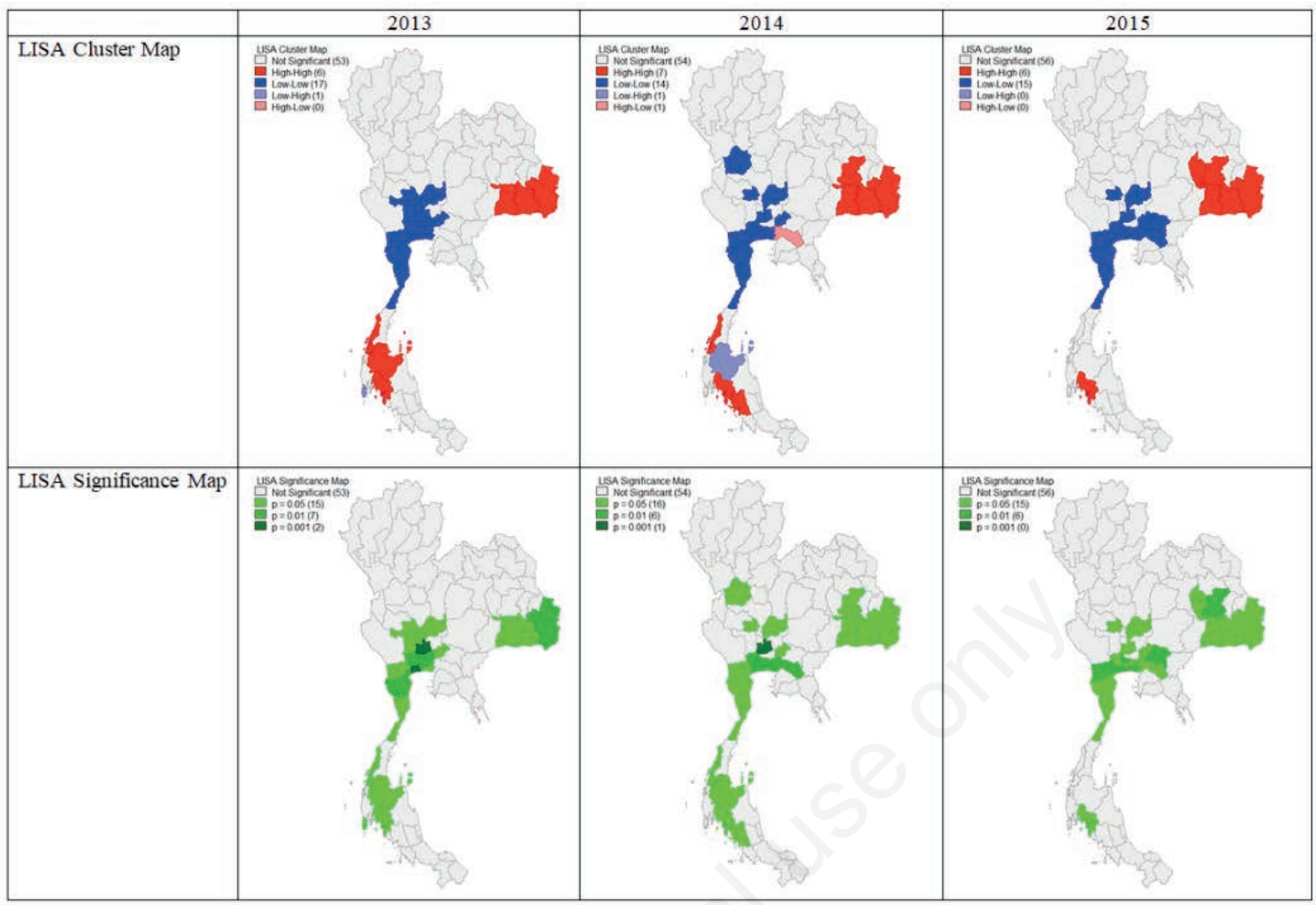

Figure 5. Spatial heterogeneity of leptospirosis in Thailand from 2013 to 2015 obtained with the local indicators of spatial association (LISA) statistic.

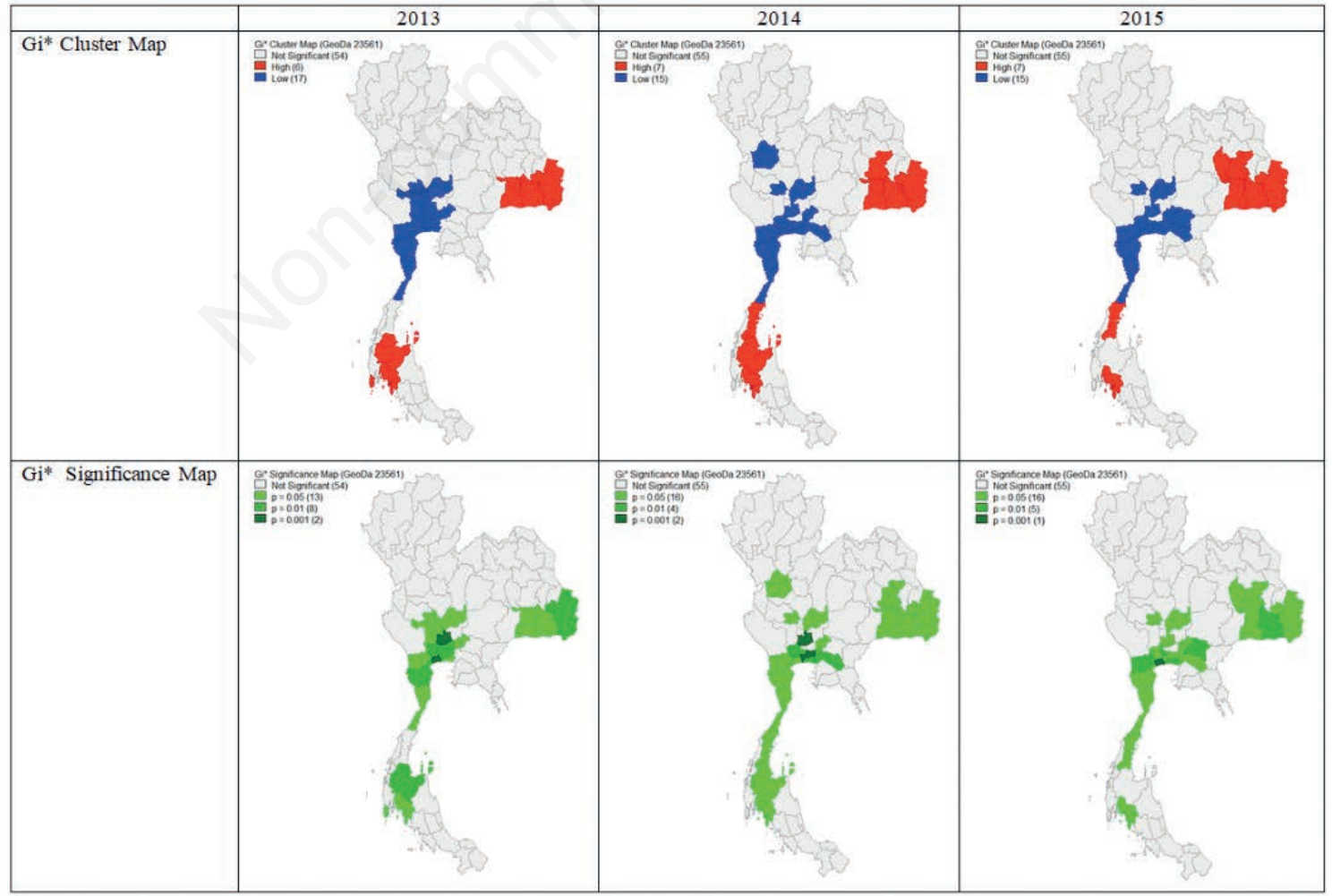

Figure 6. Spatial heterogeneity of leptospirosis in Thailand from 2013 to 2015 obtained by the Getis-Ord Gi* statistic. 
location (Tangkanakul, 2017), its link to the annual cycle of rice cultivation in Thailand can be established. The annually cyclical pattern of epidemics found in this study matches the crop cycle of rice, which starts in May and ends in January. Its association with leptospirosis epidemics is believed to be due to rainfall leading to accumulated soil moisture which is preferred by Leptospira (Lau, 2012). It is therefore to be expected that people will be at a higher risk for exposure during agricultural activities (Victoriano et al., 2009; Suwanpakdee et al., 2015). Since rainfall also induces flooding where the water is often contaminated by urine from infected animals, epidemics not only occur but are also extended causing high numbers of human leptospirosis (Faine, 1994). This is consistent with key finding of previous studies demonstrating that there is a correlation between rainfall and this kind of epidemics (Triampo et al., 2007; Chadsuthi et al., 2012; Skouloudis et al., 2015; Ledien et al., 2017). Moreover, we found that the highest number of patients occurs in October. This was especially pronounced in 2013 and there was also a previous endemic period in 2010 reaching $14.6 \%$ prevalence of infection. Our results are in accordance with the principle that people engaged in agriculture and fishery are particularly vulnerable to the disease. It is highly possible that the number of leptospirosis cases was high because most of people working in the agricultural sector are engaged in outdoor activities on their farmlands.

The results obtained from the cluster detection methods applied confirm that the clusters were mostly located in the northeastern and southern regions of the country. Based on this empirical evidence, it can be concluded that leptospirosis is a serious public health problem in Thailand, especially in these regions. With this finding, it is suggested that future studies should focus on more specific factors such as the urban density, crop season, rainfall and humidity because these variables influence the spatial and temporal patterns of leptospirosis.

\section{Conclusions}

This study highlights the key contributions of LISA and the local Getis-Ord Gi* statistic in the detection of spatial clusters, and also suggests the reallocation of resources in healthcare in order to improve the effectiveness of prevention and hospitalization toward the lower rate of leptospirosis. Both these techniques were effective in investigating the spatio-temporal patterns of leptospirosis and underlining also that the north-eastern and southern regions of Thailand were the two areas with the highest degree of leptospirosis clustering.

\section{References}

Anselin L, 1995. Local indicators of spatial association - LISA. Geogr Anal 27:93-115.

Chadsuthi S, Bicout DJ, Wiratsudakul A, Suwancharoen D, Petkanchanapong W, Modchang C, Triampo W, Ratanakorn P, Chalvet-Monfray K, 2017. Investigation on predominant Leptospira serovars and its distribution in humans and livestock in Thailand, 2010-2015. PLoS Negl Trop Dis 11:e005228.

Chadsuthi S, Modchang C, Lenbury Y, Iamsirithaworn S, Triampo W, 2012. Modeling seasonal leptospirosis transmission and its association with rainfall and temperature in Thailand using time-series and ARIMAX analyses. Asian Pac J Trop Dis 5:539-46.

Faine S, 1994. Leptospira and leptospirosis. CRC Press, Boca Raton, FL, USA.

Getis A, Ord JK, 1992. The analysis of spatial association by use of distance statistics. Geogr Anal 24:189-206.

Heisey GB, Nimmanitya S, Karnchanachetanee C, Tingpalapong M, Samransamruajkit S, Hansukjariya P, Elwell MR, Ward, GS, 1988. Epidemiology and characterization of leptospirosis at an urban and provincial site in Thailand. Southeast Asian J Trop Med Public Health 19:317-22.

Honarmand H, Eshraghi S, 2011. Detection of Leptospires serogroups, which are common causes of human acute leptospirosis in Guilan, Northern Iran. Iran J Public Health 40:107-7.

Lau CL, Clements ACA, Skelly C, Dobson AJ, Smythe LD, Weinstein P, 2012. Leptospirosis in American Samoa - estimating and mapping risk using environmental data. PLoS Negl Trop Dis 6:e1669.

Ledien J, Sorn S, Hem S, Huy R, Buchy P, Tarantola A, Cappelle J, 2017. Assessing the performance of remotely-sensed flooding indicators and their potential contribution to early warning for leptospirosis in Cambodia. PloS One 12:e181044.

Levett PN, 2001. Leptospirosis. Clin Microbiol Rev 14:296-326.

Ministry of Public Health (MoPH), 2006. National Disease Surveillance 2000-2006. The War Veterans Organization of Thailand. Available from: http://203.157.15.110/boeeng/annua 1.ph p ? fbclid=Iw A R 1 - d t Z_U __ q C z B j 9 E SYm4SvKSyJTsInoqfkiWDtxW1MqeGNijwQHIBX7g

Mitchell A, 1999. The ESRI guide to GIS analysis: Geographic patterns and relationships. ESRI Press, Redlands, CA, USA.

Myint KS, Gibbons RV, Murray CK, Rungsimanphaiboon K, Supornpun W, Sithiprasasna R, Gray MR, Pimgate C, Mammen MP Jr, Hospenthal DR, 2007. Leptospirosis in Kamphaeng Phet, Thailand. Am J Trop Med Hyg 76:135-8.

National Disease Surveillance, 2019. Report 506. Available from: http://www.boe.moph.go.th/boedb/surdata/index.php

Panaphut T, Domrongkitchaiporn S, Thinkamrop B, 2002. Prognostic factors of death in leptospirosis: a prospective cohort study in Khon Kaen, Thailand. Int J Infect Dis 6:52-9.

Parker J, Walker M, 2011. Survival of a pathogenic Leptospira serovar in response to combined in vitro $\mathrm{pH}$ and temperature stresses. Vet Microbiol 152:146-50.

Ridzlan FR, Bahaman AR, Khairani-Bejo S, Mutalib AR, 2010. Detection of pathogenic Leptospira from selected environment in Kelantan and Terengganu, Malaysia. Trop Biomed 27:6328.

Skouloudis AN, Rickerby DG, 2015. In situ and remote sensing networks for environmental monitoring and global assessment of leptospirosis outbreaks. Procedia Eng 107:194-204.

Steiniger S, Hunter AJ, 2013. The 2012 free and open source GIS software map - A guide to facilitate research, development, and adoption. Comput Environ Urban Syst 39:136-50.

Suwanpakdee S, Kaewkungwal J, White LJ, Asensio N, Ratanakorn P, Singhasivanon P, Day NPJ, Pan-Ngum W, 2015. Spatio-temporal patterns of leptospirosis in Thailand: is flooding a risk factor? Epidemiol Infect 143:2106-15.

Tangkanakul W, 2017. Containment of Leptospirosis. J Health Sci 22:526-37.

Tangkanakul W, Smits H, Jatanasen S, Ashford D, 2005. 
Leptospirosis: an emerging health problem in Thailand. Southeast Asian J Trop Med Public Health 36:281-8.

Triampo W, Baowan D, Tang IM, Nuttavut N, Wong-Ekkabut J, Doungchawee $G, 2007$. A simple deterministic model for the spread of leptospirosis in Thailand. Int J Bio Med Sci 2:22-6.

Victoriano AF, Smythe LD, Gloriani-Barzaga N, Cavinta LL, Kasai T, Limpakarnjanarat K, Ong BL, Gongal G, Hall J, Coulombe CA, Yanagihara Y, Yoshida S, Adler B, 2009. Leptospirosis in the Asia Pacific region. BMC Infect Dis 9:147.

Watt G, Jongsakul K, Suttinont C, 2003. Possible scrub typhus coinfections in Thai agricultural workers hospitalized with leptospirosis. Am J Trop Med Hyg 68:89-91.
Wiwanitkit V, 2006. A note from a survey of some knowledge aspects of leptospirosis among a sample of rural villagers in the highly endemic area, Thailand. Rural Remote Health 6:526.

World Health Organization (WHO), 2003. Human leptospirosis: guidance for diagnosis, surveillance and control. WHO, Geneva, Switzerland. Available from: http://www.who.int/ iris/handle/10665/42667. p 109.

World Health Organization (WHO), 2015. Leptospirosis Burden Epidemiology Reference Group (LERG). WHO, Geneva, Switzerland. Available from: https://www.who.int/zoonoses/ diseases/lerg/en/index $2 . h t m l$ 